\title{
PHOTOLUMINESCENCE STUDIES OF LATERAL COMPOSITION MODULATED SHORT-PERIOD AIAs/InAs SUPERLATTICES
}

E. D. JONES *, D. M. FOLLSTAEDT *, S. R. LEE *, J. L. RENO *, J. MIRECKI MILLUNCHICK **, S. P. AHRENKIEL ***, A. MASCARENHAS ***, A. G. NORMAN ***, Y. ZHANG ***, and R. D. TWESTEN ****

*Physical \& Chemical Science Center, Sandia National Laboratories, Albuquerque, NM 87185

**Department of Materials Science \& Engineering, University Michigan, Ann Arbor, MI 48109

***National Renewable Energy Laboratory, Golden, CO 80401

****Center for Microanalysis, University of Ilinois, Urbana, IL 61801

\section{ABSTRACT}

DEC.EIVED

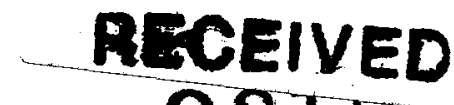

JA $\Phi_{1}$ I $_{\text {Igg }}$

$U \rightarrow r$

We present low temperature photoluminescence data for a series of spontaneous lateral composition modulation in (AlAs) $)_{\mathrm{m}} /(\mathrm{InAs})_{\mathrm{n}}$ short period superlattices on $\mathrm{InP}$ with differing average lattice constants, i.e., varying global strain. The low temperature photoluminescence peak energies were found to be much lower than the corresponding energy expected for the equivalent $\mathrm{In}_{\mathrm{x}} \mathrm{Al}_{1-\mathrm{x}} \mathrm{As}$ alloy. The bandgap energy reductions are found to approach $500 \mathrm{meV}$ and this reduction is found to correlated with the "strength" of the composition modulation wave amplitude.

\section{INTRODUCTION}

Spontaneous lateral composition modulation (CM) resulting from the deposition of short period superlattices (SPS) is a relatively phenomenon. Recently, a review for the formation and status of CM was presented by Mirecki Millunchick, et. al. [1]. Lateral CM in short period superlattices has been observed for a variety of material systems such as $(\mathrm{InP})_{\mathrm{m}} /(\mathrm{GaP})_{\mathrm{n}}$ on $\mathrm{GaAs}[2,3]$, $(\operatorname{InAs})_{\mathrm{m}} /(\mathrm{GaAs})_{\mathrm{n}}$ on $\operatorname{InP}[4,5]$, and $(\mathrm{AlAs})_{\mathrm{m}} /(\mathrm{InAs})_{\mathrm{n}}$ on $\operatorname{InP}$ [6-11]. Here $\mathrm{m}$ and $\mathrm{n}$ are the number of monolayers (ML) of each binary compound deposited. For these materials and growth conditions, the lateral CM wave is observed along the [110] direction although deviations of this rule have recently been reported $[10,11]$.

In this work, we will present low temperature photoluminescence (PL) data for a series of $(\mathrm{AlAs})_{\mathrm{m}} /(\mathrm{InAs})_{\mathrm{n}}$ SPS samples on InP with differing average lattice constants, i.e., varying global strain. Lattice constant variation was achieved by changing the ratio of the layer-thickness of InAs compared to AlAs and at the same time, constraining the superlattice period to range between about 1.5 and 4 monolayers. In this manner, the global strain in the short period superlattice could be adjusted from tensile to compressive.The low temperature PL peak energies are found to be much lower than the corresponding bandgap energy expected for the concentration equivalent InAlAs alloy. These bandgap energy reductions approach $500 \mathrm{meV}$ and found to depend with the "strength" of the composition modulation wave amplitude.

The (AlAs) ${ }_{m} /(\operatorname{InAs})_{n}$ SPS were grown by molecular beam epitaxy techniques on (001) InP at $530^{\circ} \mathrm{C}$ under As-rich conditions. A buffer layer of approximately lattice matched, random alloy InAlAs was deposited on the InP substrate. The buffer was grown at $0.7 \mathrm{ML} / \mathrm{s}$, while the individual SPS layers were grown at approximately one-half this rate. The $(\mathrm{InAs})_{\mathrm{n}} /(\mathrm{AlAs})_{\mathrm{m}}$ SPS with $\mathrm{n}+$ $\mathrm{m}$ ranging between 1.5 and 4 was deposited on top of the InAlAs buffer. Nominally, 150-period SPS structures were grown. Finally, a $0.5-\mu \mathrm{m}$-thick cap layer of undoped $\operatorname{In}_{0.53} \mathrm{Ga}_{0.47} \mathrm{As}$ was 


\section{DISCLAIMER}

This report was prepared as an account of work sponsored by an agency of the United States Government. Neither the United States Government nor any agency thereof, nor any of their employees, make any warranty, express or implied, or assumes any legal liability or responsibility for the accuracy, completeness, or usefulness of any information, apparatus, product, or process disclosed, or represents that its use would not infringe privately owned rights. Reference herein to any specific commercial product, process, or service by trade name, trademark, manufacturer, or otherwise does not necessarily constitute or imply its endorsement, recommendation, or favoring by the United States Government or any agency thereof. The views and opinions of authors expressed herein do not necessarily state or reflect those of the United States Government or any agency thereof. 


\section{DISCLAIMER}

Portions of this document may be illegible in electronic image products. Images are produced from the best available original document. 
Table 1: PROPERTIES FOR (AIAs)/(InAs) SPS

\begin{tabular}{|c|c|c|c|c|c|c|}
\hline $\begin{array}{c}\text { SAMPLE } \\
\#\end{array}$ & $\begin{array}{c}\mathrm{N} \\
(\mathrm{ML})\end{array}$ & $\begin{array}{c}\mathrm{M} \\
(\mathrm{ML})\end{array}$ & $\begin{array}{c}\text { X-RAY } \\
\text { INTENSITY } \\
\text { (ARB. UNITS }\end{array}$ & $\begin{array}{l}\text { INDIUM } \\
\text { (X) }\end{array}$ & $\begin{array}{c}\text { STRAIN: } \\
\text { E-PARALLEL } \\
(\%)\end{array}$ & $\begin{array}{c}\text { PL } \\
\text { ENERGY } \\
(\mathrm{meV})\end{array}$ \\
\hline EA0117 & 1.67 & 2.10 & 18.2 & 0.442 & +0.538 & 1293.2 \\
\hline EA0118 & 1.91 & 2.15 & 65.5 & 0.470 & +0.346 & 1100.9 \\
\hline EA0119 & 1.87 & 1.96 & 55.7 & 0.488 & +0.221 & 1049.6 \\
\hline EA0120 & 2.06 & 1.83 & 67.3 & 0.529 & -0.052 & 1010.1 \\
\hline EA0121 & 1.60 & 2.18 & 0 & 0.422 & +0.673 & 1540.2 \\
\hline EA0122 & 1.85 & 2.13 & 66.6 & 0.466 & +0.368 & 1099.6 \\
\hline EA0147 & 1.87 & 1.75 & 69.6 & 0.518 & +0.016 & 1040.8 \\
\hline EA0149 & 1.79 & 1.51 & 49.0 & 0.543 & -0.148 & 1070.0 \\
\hline EA0150 & 1.78 & 1.34 & 50.0 & 0.571 & -0.338 & 1053.0 \\
\hline EA0151 & 1.69 & 1.17 & 42.6 & 0.590 & -0.465 & 1060.8 \\
\hline EA0168 & 1.69 & 2.00 & 43.2 & 0.458 & +0.425 & 1145.4 \\
\hline EA0180 & 1.65 & 0.96 & 0 & 0.631 & -0.707 & 981.8 \\
\hline EA0184 & 1.98 & 1.95 & 60.637 & 0.505 & +0.124 & 1014.2 \\
\hline
\end{tabular}

added to the top of the SPS to prevent oxidation of the AlAs layers. The growth rates were calibrated in situ using reflection high-energy electron diffraction oscillations. The composition and strain of the buffer and SPS were also determined with lattice spacings from x-ray diffraction. In assessing the average strain of the SPS, we assumed that its composite elastic properties are like those of a random alloy, and then used the measured out-of-plane strain to deduce the average inplane strain and layer composition. Here, strain is defined as the difference between the observed in-plane lattice constant and that of the material as a free-standing layer. The presence or lack of CM was confirmed using cross-section TEM and $\mathrm{x}$-ray reciprocal space analysis [12]. A summary of all results are presented in Table 1 . The integrated intensity of the reciprocal space X-ray measurements is a measure of the strength of the composition modulation wave amplitude [9]. In Table 1, the X-ray intensity of zero value for samples EA0120 and EA0180 indicate that no CM was observed by any technique. A plot of the integrated $x$-ray intensity as a function of indium concentration is shown in Fig. 1. The smooth curve drawn through the experimental points is meant to be a guide for the eye and has no theoretical interpretation.

The photoluminescence spectroscopy measurements were made at $4.0 \mathrm{~K}$ The $\mathrm{CM}$ samples were attached to the end of a $100 \mu \mathrm{m}$-core-diameter optical fiber and placed in a liquid helium storage dewar. The PL measurements were made with an Argon-ion laser operating at $514.5 \mathrm{~nm}$. The laser was injected into the optical fiber by means of an optical beam-splitter and the returning photoluminescence signal was directed to a 0.27 -meter, f/4 optical monochromator and a IEEE488-based data acquisition system. Typical laser power densities on the sample were of the order of $1 \mathrm{~W} / \mathrm{cm}^{2}$ and a NORTH COAST EO-817 germanium detector was used to record the infrared energy photons. The 4-K luminescence peak energy for each sample is tabulated in Table 1 . The low temperature PL spectrum for sample EA0184 is shown in Fig. 2 where the main PL peak near $1000 \mathrm{meV}$ is that from the indium-rich (lowest energy) bandgap portion of the (AlAs) $/(\operatorname{InAs})_{n}$ SPS CM wave. The high energy peak near $1500 \mathrm{meV}$ is from the nominally lattice-matched InAlAs buffer layer, while the PL peak at $800 \mathrm{meV}$ is from the InGaAs cap layer. The line shape 
or linewidth of the CM PL spectrum will not be discussed here, but undoubtedly, contributions from a combination of residual strain and varying (inhomogeneous) indium concentration in the CM region are important.

\section{DISCUSSION}

Figure 3 is plot of the PL energy data given in Table 1 as a function of the indium concentration. Also shown is the corresponding concentration dependence of the bandgap energies for unstrained (dashed line) and strained (solid line) $\mathrm{In}_{\mathrm{x}} \mathrm{Al}_{1-\mathrm{x}}$ As alloy on InP. The concentration dependence for unstrained $\operatorname{In}_{x} \mathrm{Al}_{1-\mathrm{x}}$ As bandgap energy $\mathrm{E}^{\mathrm{U}}(\mathrm{X})$ at $4 \mathrm{~K}$ is given by [13]

$$
E^{U}(X)=3110-3395 X+725 X^{2}
$$

where $\mathrm{X}$ is the indium concentration. In order to make meaningful comparison to the strained (AlAs) $)_{m} /(\text { InAs })_{n}$ SPS structures, the effect on the bandgap energy by the coherent biaxial strain on coherently strained $\operatorname{In}_{\mathrm{x}} \mathrm{Al}_{1-\mathrm{x}}$ As alloy must be considered and is easily calculated with the result

$$
E^{S}(X)=E^{U}(X)+2 a \frac{C_{11}-C_{12}}{C_{11}} \varepsilon_{x x}-\left|2 b \frac{C_{11}+C_{12}}{C_{11}} \varepsilon_{x x}\right| \text {, }
$$

where corrections due to the spin-orbit induced split-off valence-band have been ignored. In Eq. (2), $a$ and $b$, are respectively the volume and biaxial deformation potentials, $C_{11}$, and $C_{12}$ are the

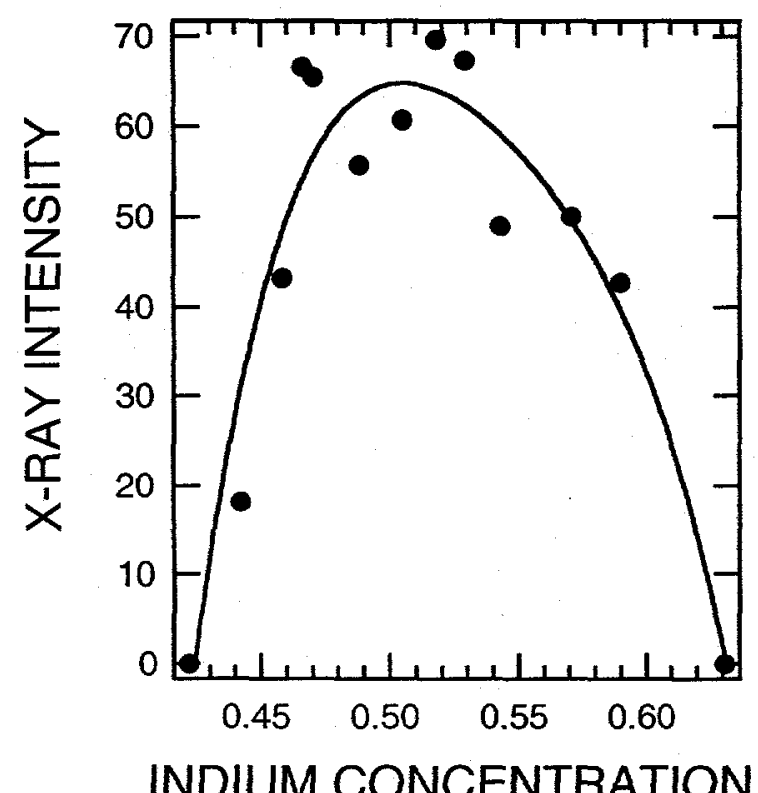

Figure 1. Plot of the integrated $x$-ray intensity given as a function of the indium concentration, listed in Table I. The smooth curve drawn through the data is provided as an aid to the eye.

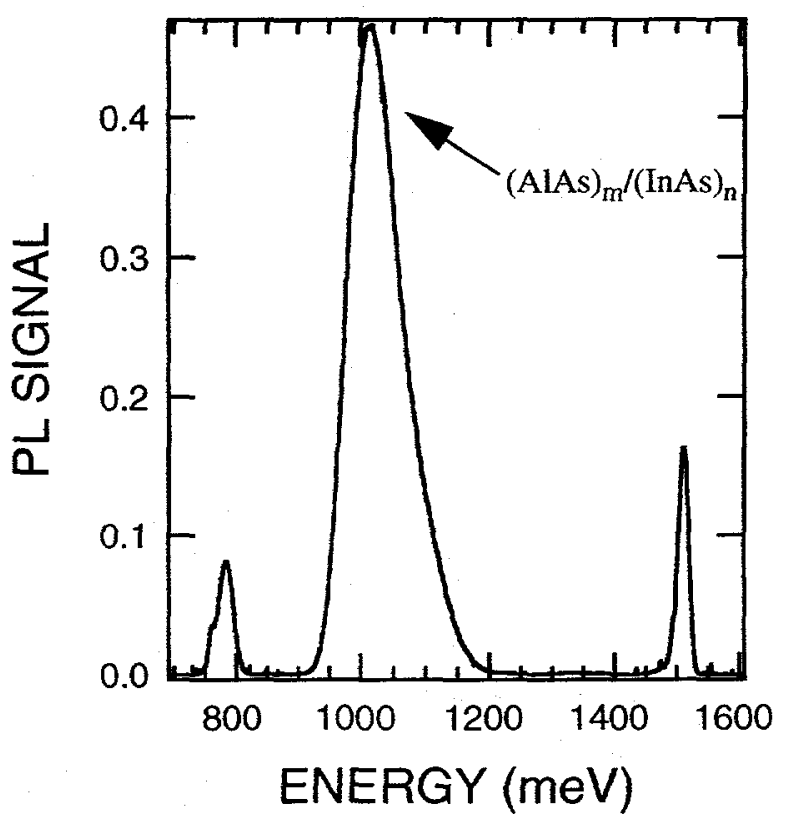

Figure 2. PL spectrum for sample EA0184 at $4 \mathrm{~K}$. The PL peak near $1000 \mathrm{meV}$ is from the CM layer of the sample. The high and low energy PL peaks are respectively from the InAlAs buffer and the InGaAs cap layer. 
Table 2: Physical Parameters for AIAs and InA

\begin{tabular}{|l|c|c|}
\hline \multicolumn{1}{|c|}{ Physical Property } & AlAs & InAs \\
\hline \hline Lattice Constant $(\AA), \mathrm{d}_{\text {InP }} \equiv 5.8686 \AA$ & 5.6613 & 6.0584 \\
\hline Elastic Constant $\mathrm{C}_{11}\left(10^{11}\right.$ dynes $\left./ \mathrm{cm}^{2}\right)$ & 11.63 & 8.663 \\
\hline Elastic Constant $\mathrm{C}_{12}\left(10^{11}\right.$ dynes $\left./ \mathrm{cm}^{2}\right)$ & 5.76 & 4.848 \\
\hline Deformation Potential a (eV) & -10.2 & -6.26 \\
\hline Deformation Potential b (eV) & -1.5 & -1.8 \\
\hline
\end{tabular}

$s \quad$ elastic constants, and $\varepsilon_{\mathrm{xx}}$ is the in-plane strain. Because the biaxial strain splits the degenerate alloy valence bands, the bandgap energy is always decreased by the biaxial term, independent of which valence-band is the ground state, i.e., when the lattice is in tension or compression, there is a reversal of the symmetry of the valence-band ground state, but the bandgap energy is always decreased. Because the PL transition is between the two lowest energy states, conduction and

valence-band, we use the absolute function in the third term of Eq. (2) to account for the biaxial strain reduction of the bandgap energy. The physical parameters used in this paper for AlAs and InAs are listed in Table 2. The in-plane strain $\varepsilon_{\mathrm{xx}}$ (or lattice mismatch), tabulated in Table 1, is defined in terms of the lattice constants $\mathrm{d}_{\text {InAlAs }}$ and $\mathrm{d}_{\text {InP }}$ by

$$
\varepsilon_{\mathrm{xx}}=\frac{d_{\text {InAlAs }}-d_{I n P}}{d_{\text {InAlAs }}}
$$

We now calculate the bandgap reduction for the indium-rich part (AlAs) $)_{m} /(\operatorname{InAs})_{n}$ SPS CM wave. This is accomplished by subtracting the observed PL bandgap energy shown in Fig 3 (and also tabulated in Table 1) from the calculated $\operatorname{In}_{x} \mathrm{Al}_{1-\mathrm{x}} \mathrm{As}$ strained bandgap energy (Eq. (2)) for each indium concentration.

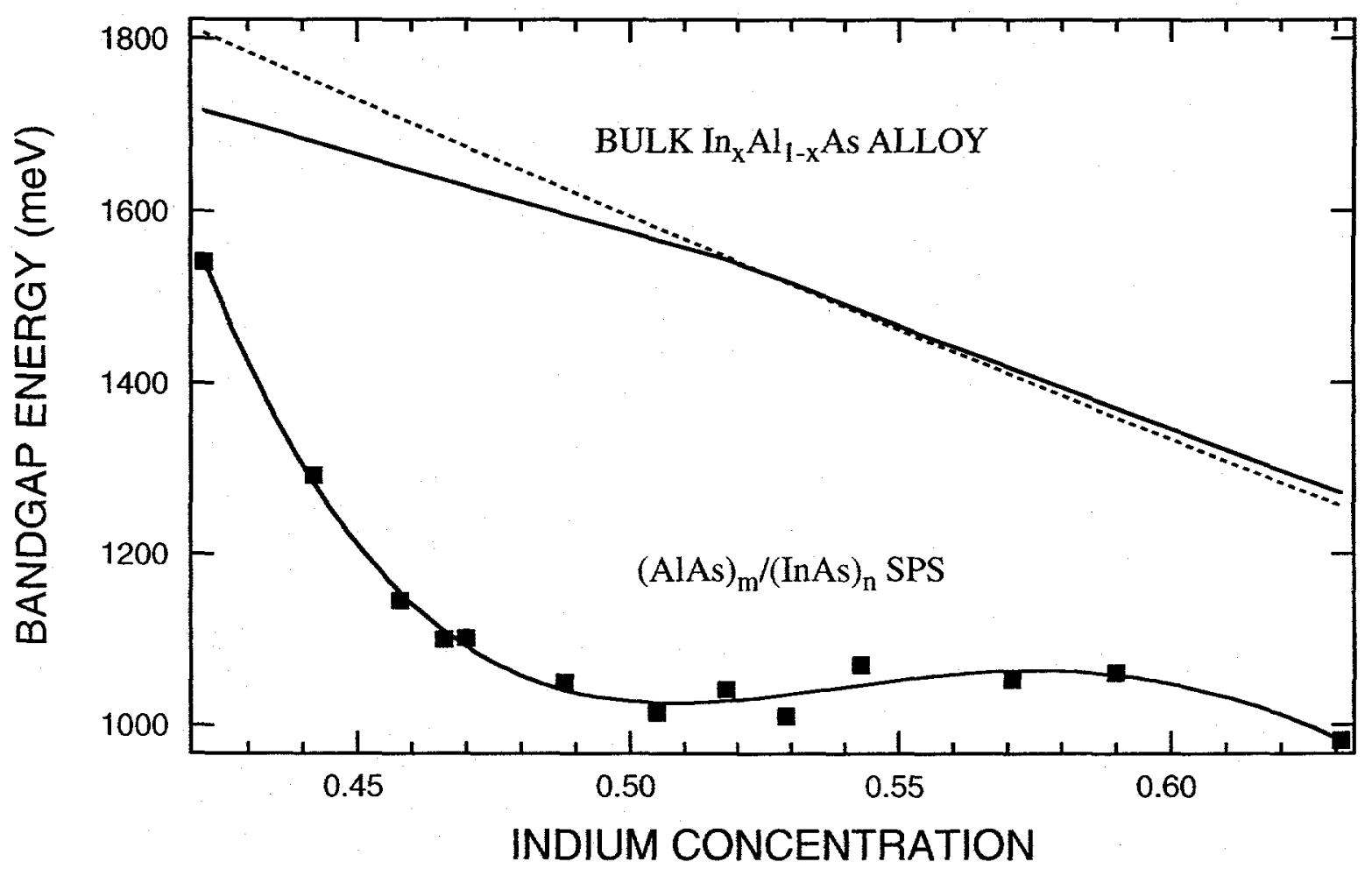

Figure 3. CM bandgap energy versus indium concentration. The bandgap energy for coherently strained (solid) and unstrained (dashed) is also shown for bulk $\operatorname{In}_{\mathrm{x}} \mathrm{Al}_{1-\mathrm{x}} \mathrm{As}$. 


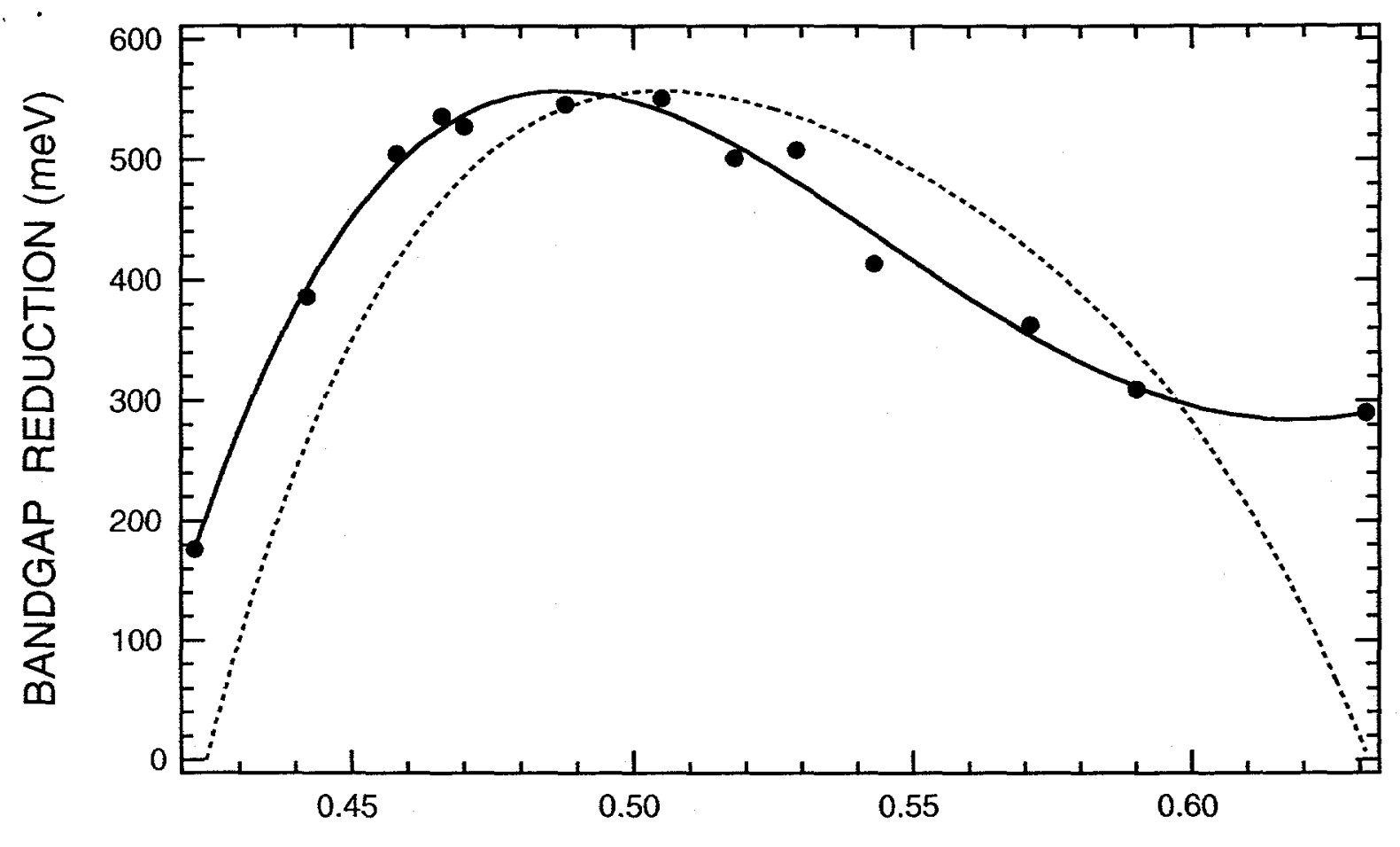

INDIUM CONCENTRATION

Figure 4. Bandgap reduction energy versus indium concentration. The solid line drawn is a smooth curve to aid the eye. The dashed line is the corresponding $x$-ray intensity versus indium curve shown in Fig. 1.

Figure 4 shows the bandgap energy reduction for all of the samples listed in Table 1. Also shown (dashed line) is the X-ray intensity data shown Fig 1. As can be seen in the Figure, there is a strong correlation between the x-ray intensity data (Fig. 1) and the bandgap energy reduction, i.e., the maximum reduction occurs for those samples with the largest $\mathrm{x}$-ray intensities. As discussed by Zhang and Mascarenhas [14], there are two contributions to the bandgap energy reduction. The first is a structural effect due to the (100)-oriented SPS and the second is that due to CM and may be as large as $400 \mathrm{meV}$ for our samples. For no CM, SPS monolayers of AlAs and InAs result in a CuAu-type structure and it is estimated [14] that the bandgap reduction is about 100 meV. For sample EA0121, this $100 \mathrm{meV}$ reduction is reasonable with the observed reduction of about $175 \mathrm{meV}$, especially in view of the fact that EA0121 is not a monolayer SPS. However, the same conclusion does not hold for the indium-rich EA0180 (no CM) where the reduction is $\sim 300$ meV. Zhang and Mascarenhas [14] also show that the that large CM diminishes the CuAu-order and hence the energy reduction. Twesten [15] has performed scanning TEM measurements on sample EA0184 and finds that the maximum indium concentration in the CM wave is 0.76 . The energy for strained $\mathrm{In}_{0.76} \mathrm{Al}_{0.24} \mathrm{As}$ is somewhat lower than the bandgap energy for EA0184 suggesting that the reduction due to the $\mathrm{CuAu}$-ordering is negligible, but confirming the presence of large CM. This negative energy difference also suggests quantum confinement may play a role.

\section{CONCLUSIONS}

We have presented low temperature PL data for a large number of (AlAs $)_{m} /(\text { InAs })_{n}$ SPS structures on InP with varying degrees of CM. We find that when there is evidence for strong CM, the is a large bandgap energy reduction in the PL energy. These results compare favorably with the recent theoretical treatment for bandgap reduction by Zhang and Mascarenhas [14]. 


\section{ACKNOWLEDGEMENTS}

This work was supported in part by the Division of Material Science, Office of Basic Energy Science, U. S. DOE, DE-AC04-94AL8500 and DE-AC02-83-GHt19093 thultiprogram laboratory operated by Sandia Corporation, a Lockheed Martin Company, for the REFERENCES United States Department of Energy under contract DE-AC04-94AL85000.

1. J. Mirecki Millunchick, R. D. Twesten, S. R. Lee, D. M. Follstaedt, E. D. Jones, S. P. Ahrenkiel, Y. Zhang, H. M. Cheong, and A. Mascarenhas, MRS Bulletin 22, 38 (1997).

2. A. C. Chen, A. M. Moy, L. J. Chou, K. C. Hsieh, and K. Y. Cheng, Appl. Phys. Lett. 66, 2694 (1995).

3. J. Yoshida, K. Kishino, D. H. Jang, S. Nahm, I. Nomura, A. Kikuchi, Optical and Quantum Electronics 28, 547(1996).

4. S. T. Chou, K. Y. Cheng, L. J. Chou, K. C. Hsieh, J. Appl. Phys. 786270 (1995).

5. S. T. Chou, K. C. Hsieh, K. Y. Cheng, L. J. Chou, J. Vac. Sci. Technol B13 , 650 (1995).

6. J. Mirecki Millunchick, R. D. Twesten, D. M. Follstaedt, S. R. Lee, E. D. Jones, Y. Zhang, S. P. Ahrenkiel, and A. Mascarenhas, Appl. Phys. Lett. 70, 1402 (1997).

7. J. Mirecki Millunchick, R. D. Twesten, S. R. Lee, D. M. Follstaedt, E. D. Jones, S. P. Ahrenkiel, Y. Zhang, H. M. Cheong, and A. Mascarenhas, J. Electronic Materials 26, 1048 (1997).

8. D. M. Follstaedt, R. D. Twesten, J. Mirecki Millunchick, S. R. Lee, E. D. Jones S. P. Ahrenkiel, Y. Zhang and A. Mascarenhas, Physica E 2, 325 (1997).

9. R. D. Twesten, J. Mirecki Millunchick, S. P. Ahrenkiel, Y. Zhang, S. R. Lee, D. M. Follstaedt, A. Mascarenhas, and E. D. Jones in Thin Films-Structure and Morphology, edited by S. C. Moss, D.Ila, R.C. Cammarata, E.H. Chason, T.L. Einstein, and E.D. Williams, (Mater. Res. Soc. Proc. 441, Pittsburgh, PA, 1997), pp. 187-191

10. A. G. Norman, S. P. Ahrenkiel, H. Moutinho, M. M. Al-Jassim, A. Mascarenhas, J. Mirecki Millunchick, S. R. Lee, R. D. twesten, D. M. Follstaedt, and E. D. Jones, Appl. Phys. Lett. 73, 1844 (1998).

11. S. P. Ahrenkiel, A. G. Norman, M. M. Al-Jassim, A. Mascarenhas, J. Mirecki-Millunchick, R. D. Twesten, S. R. Lee, D. M. Follstaedt, and E. D. Jones, J. Appl. Phys. 84, 6088 (1998).

12. S. R. Lee, J. Mirecki Millunchick, R. D. Twesten, D. M. Follstaedt, J. L. Reno, S. P. Ahrenkiel, and A. G. Norman, Accepted for Publication in Jr. Materials Science: Materials in Electronics.

13. I. J. Fritz (Private Communication)

14. Y. Zhang and A. Mascarenhas, Phys. Rev. B57 , 12245 (1998).

15. R. D. twesten (Unpublished) 